\title{
Business-to-business and self-governance practice in the digital knowledge economy: learning from pharmaceutical e-detailing in Thailand
}

\section{Ronan de Kervenoael ${ }^{1}\left(\mathbb{D} \cdot\right.$ Alexandre Schwob $^{2} \cdot$ Inci Toral Manson $^{3}$. Chatlada Ratana ${ }^{4}$}

Received: 30 January 2020 / Revised: 7 October 2020 / Accepted: 15 October 2020 /

Published online: 30 October 2020

(c) Springer Nature Limited 2020

\begin{abstract}
This study investigates self-governance within business-to-business (B2B) in the digital knowledge economy. To do so, we elicit the engagement of healthcare professionals (HCPs) and medical science liaisons (MSLs) with "for-profit social media technology" (FPSMT) in e-detailing. Using data from 23 in-depth interviews with HCPs (physicians and pharmacists) and MSLs in Thailand, we show that e-detailing fosters self-governance as a practice. The data identify how FPSMT, as privatized social media managed by large firms, represents a tool for self-governance that is articulated by expert professionals along three cognitive frames: aspiration, regulation, and responsibilisation. Through FPSMT, professionals in highly regulated $\mathrm{B} 2 \mathrm{~B}$ ecosystems engage in self-governance practice to develop pooled views that are influenced by personal and collective rules. The perspective on self-governance as a practice that is offered allows to understand how B2B network governance rely on professionals' engagement to foster aspirations for the collective agenda, beyond the narrow pursuit of sales' objectives.
\end{abstract}

Keywords B2B $\cdot$ Thailand $\cdot$ Social media technology $\cdot$ Healthcare $\cdot$ Selfgovernance $\cdot$ Technological framing $\cdot$ Network governance

\section{Introduction}

Self-governance delineates the process whereby one is "having control over oneself, to act in a way that is relevant to one's own profession, to know who you are and, therefore, behave in the way your profession expects" (McTaggart et al. 2017, p. 90). Despite widespread research on self-governance in political sciences and management literature, there is a scarcity of studies addressing the forms self-governance

Ronan de Kervenoael

ronan.jouan-de-kervenoael@rennes-sb.com

Extended author information available on the last page of the article

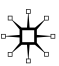


takes to face the needs of Asian' firms within the digital knowledge economy (Wang et al. 2016). Within today's hyperconnected economies, self-governance is so far depicted as accomplished through knowledge work that has often been equated to self-branding (Gandini 2016; Grénman et al. 2019). In this research, we propose an enlarged view on self-governance that establishes how individuals demonstrate their sense of professionalism while appreciating existing governance structures that prevail in inter-firm relationships (Chelariu and Sangtani 2009). This view allows to approach self-governance as a practice occurring in today's digitized environments that fuel innovation in settings where relationships are very tightly organized, as is the case in business-to-business (B2B) relationships (Fox and Ward 2008; Olakivi and Niska 2017).

In this paper, we investigate the unfolding of self-governance practice within the digital knowledge economy by examining the B2B case of pharmaceutical e-detailing in Thailand. E-detailing represents the main access point leveraged by MedTech firms via their medical science liaisons (MSLs) to engage healthcare professionals (HCPs). It helps to manage access to information including sales content, on multiples devices, making new product information (e.g., drugs, delivery mechanisms, test studies, etc.) interactive and updated in real time. Importantly, because of its strategic importance, e-detailing is strictly regulated revealing, how HCPs' engagement with SMT meets both novel and often conflicting expectations stemming from social media platforms owned by private large pharmaceutical brands that we call 'for-profit social media technology' (FPSMT). We analyze self-governance practice through twenty-three in-depth semi-structured interviews with MSLs and HCPs (including pharmacists and physicians) as key users of e-detailing systems. The data show how HCPs and MSLs are engaged with FPSMT, indicating that such technology requires them to develop their own sense of professionalism while appreciating how to comply with governance structures that concern both public (patients, governments, NGOs) and private stakeholders. The findings show that digitized self-governance supports Asian firms' innovation management by enabling expert professionals to articulate collaborative behaviors and the pursuit of sales objectives with the management of their own reputation.

Set in the framework of these broad challenges, we pursue two main objectives: (1) to address in B2B how HCPs make sense of their current situations when cognising, drawing on, and leveraging their engagement with FPSMT in e-detailing; and (2) to identify the main drivers and manifestations of self-governance in practice that occur through B2B market-actors' engagement with FPSMT. To accomplish this, we adopt an approach based on framing and sensemaking that sheds light on the ambiguities and paradoxes that technology implies. We show how HCPs and MSLs are empowered to unravel SMT's unsettled structures and take actions, while at the same time, leaving scope for dissonance and situational improvisation (Goffman 1974; Mazmanian 2013; Orlikowski and Gash 1994). We then consider the theoretical contributions by revealing insights on how self-governance operates in B2B and as a practice beyond discrete experiences or desirable states for expert individuals (Gautam 2017; Gandini 2016). Self-governance is found to be a fundamental resource to invigorate network governance in the digital knowledge economy. Subsequently, learning from pharmaceutical e-detailing in Thailand, we show how for 
managers, self-governance transforms organizations and management practices by supporting an innovative and socially negotiated view on technologized networks.

\section{Theoretical framework}

\section{For-profit SMT for B2B market-actors' engagement in the digital knowledge economy}

A wide set of theories (e.g., diffusion of innovation, technology acceptance and value-added models) has been mobilized in the literature to investigate how different B2B market-actors comprehend SMTs, which are developed, codified, and retained to seize socially generated values that enhance knowledge management processes and help organizations compete (Pascucci et al. 2018; Golden 2011). In a professional context, employees' knowledge sharing via SMT is an investment in social relationships and represents individual market actor's experiential know-how (work, actions, and sociality-based practices [Marwick and Hargittai 2019]) shared during social interactions (Panahi et al. 2016). Real time information diffusion through shared learning experiences carries specific expectations about with whom it can be shared and what an increasingly freelance workforce can legally convey (Marwick and Hargittai, 2019; Wegner and Mozzato 2019). In B2B, most intranets or SMTs are a single firm's property and strictly controlled within that firm; thus, proposing a specific knowledge partaking culture (Gandini 2016; North and Kumta 2018). SMTs facilitate knowledge retention and monitor market-actors' internalization of company values and culture, including appropriate communication and respect of the legislation so that expert knowledge is not lost (Ammirato et al. 2019).

In B2B, researchers have analyzed the changing characteristics of SMT and the novel types of behavior they generate (Buratti et al. 2018; Siamagka et al. 2015). Macro-issues with SMT have mainly related to technical hurdles (Moncrief et al. 2015), underusage and unidirectionality of tools (Järvinen et al. 2012), dissemination issues (Ammirato et al. 2019), sales performance and marketing content creation (Huotari et al. 2015), firm brand-building strategy (Cawsey and Rowley 2016). At meso- and micro-levels, B2B studies have investigated SMT adoption and management's understanding (Sivalingam 2010); managers' sensemaking (Rooderkerk and Pauwels 2016); influences on business practices, sales and branding; training requirements; employee management communication (Edosomwan et al. 2011); and individual professionals' self-branding (Gandini 2016). At this point, as SMTs experience hyper-growth and hype continues in $\mathrm{B} 2 \mathrm{~B}$, the boundaries businesses establish between their employees and outside market-actors are becoming increasingly blurred, precluding the non-engagement of the latter as a viable stance (Leek et al. 2016; Razmerita et al. 2016).

FPSMT opposes the traditional understanding of SMT as allowing any individual or group to leverage and share experiences to all without specific organizational oversight or steering capacity, thus encouraging many firms and parties to capture the potential benefits. Indeed, different from the models used in e-commerce platforms (e.g., Amazon), P2P (e.g., eBay) or the circular economy (e.g., Gumtree), 
FPSMT is specifically designed to allow only selected individuals, professional groups or experts to interact and share knowledge and information. This leads to appropriation and monetisation of their ideas and data and, in effect, provides better decision support services to develop novel sales tactics, products and marketing strategies for a specific private firm (Schor 2016). Within the health ecosystem, FPSMTs are commonly used to cultivate corporate profiles, encourage pharmacy careers, and support over the counter (OTC) brands' profiles and innovation along brand communities' properties. This importantly refocuses FPSMTs on specific diseases, molecule resistance, and future innovation (Unmetric.com 2019). FPSMT privatize profits for the social media provider and socialize expenses and losses when supporting healthcare professionals (HCPs) involved in knowledge sharing on B2B platforms, thus calling upon HCPs to be attentive to violations of personal-professional boundaries including safeguarding accountability and trustworthiness of data storage (see HIPAA rules ${ }^{1}$ ).

Consequently, B2B market-actors' activities on FPSMT encourage and problematise independent individuals' social engagement in the value creation process. This engagement operates in knowledge networks and requires professionals to question and monitor the linkages between themselves and their chosen networks. As a social process, self-governance between heterogenous professionals becomes central to understanding what makes individual actions meaningful, responsible, and sustainable (de Kervenoael et al. 2015). SMT usage thus reflects preferred conduct when relating to professional peers in this new labor market (Edosomwan et al. 2011). The literature underlines that SMT allows individuals to work for themselves in securing employment because it is a supporting tool that emanates from the socialization process at work (Gandini 2016). Within these conditions, establishing the relationships between SMTs and expert market-actors' engagement is difficult because economic performance levels and heightened perceptions of (legal) risk characterize the decision process (Swani et al. 2017). On the one hand, B2B actors' engagements are encouraged, echoing the sharing economy model, which facilitates knowledge work on digitized platforms, and promotes professionals' open asset sharing, requiring outward-oriented self-development where gains/losses are often intangible and hard to measure (Grondys 2019). On the other hand, engagement in knowledge sharing depends on specific organisations' strategies (e.g., promoting corporate brands and specific selected products and hard-sell approaches) and how market-actors are affiliated with, professionals' embeddedness in pre-existing social networks (endowment effect). Market-actors' engagement thus goes along with the presence of various sets of governance procedures reflecting a wider range of social values that oscillate between progressive goals and genuine cooperation to "business as usual" that combines play and work (Schor 2016).

\footnotetext{
1 The Health Insurance Portability and Accountability Act (HIPAA) regulations are established in the United States and divided into several major standards or rules: Privacy Rule, Security Rule, Transactions and Code Sets (TCS) Rule, Unique Identifiers Rule, Breach Notification Rule, Omnibus Final Rule, and the HITECH Act. Global pharmaceutical firms apply these (with some variations) in many countries, including Thailand.
} 
The novel recombination of knowledge and its outcomes suggests innovative behavior and becomes tangible at the individual market actor level. When learning from SMTs, individuals become aware of their own expert value and capacity to understand others' perspectives, "functioning as intermediaries that transform social relationships into value" (Gandini 2016, p. 125). This allows individuals to make sense of multiple demands (e.g., economic, legal or, in our case, health) placed on market-actors by the digital knowledge economy's modes of innovation, characterized on a continuum between e-topia and dystopia and questioning whether SMTs can promote social change (Lomborg 2017). The necessary competencies identified in SMT literature are in formal areas, such as sales style and customer relationship management (Ammirato et al. 2019) or telemarketing (Moncrief et al. 2015), and less formal areas, including networking, problem-solving skills, and leadership capabilities (Wathne and Fjeldstad 2019)_but all aim at driving socio-economic growth (North and Kumta 2018).

In this context, digital transformation and SMTs as becoming increasingly more complex to manage (Swani et al. 2017) and stressed rapidly evolving transformative capability building is needed among highly skilled and specialized professionals (Baptista et al. 2017; Van den Berg and Verhoeven 2017). B2B professionals' concerns for private and collective agenda that are present on daily usage of FPSMT calls for an understanding of their engagement in the value creation processes based on collaborative and competitive modes of conduct and how the structuring and uncertain outcomes of the latter have consequences on network governance (Wegner and Mozzato 2019).

\section{Knowledge work, network governance, and self-governance through SMT}

Knowledge work can be defined as actions market-actors take to solve problems whereby not only the state or large institutionalized actors regulate behavior (i.e., going across public-private boundaries of the classical liberal movement). Often, many actors operate in networks across multiple mechanisms (legal, market, and social) to foster a continuous exchange process to tackle specific complex issues for which local expertise becomes important (Esmark and Triantafillou 2009; Parker 2007). Both convergent and divergent reasoning on what is active interaction on SMT is required to cope with today's complex and dynamic knowledge economy management beyond the meso-level theories traditionally considered in governance research (Burchell et al. 1991; North and Kumta 2018). As strategic assemblages, SMT engagement influences how market-actors critically sense and act within specific professional domains to create a coherent knowledge framework. In support, network governance is designed to capture decentralized decision-making systems where actors are connected by ties and share power and information reflecting their practices and world views. Within network governance, an actor's participation is based on recognition and trust and how both affect and are affected by the behavior of other actors (Davies 2000). Studies on knowledge work in networked technologies underline the importance of positive coping together with positive computing design (Clarke 2018), but these have often bracketed in their focus network settings 
in which the exercise of power, authority, and influence for "getting things done" (Stoker 1998, p. 24) have to be operant.

In interorganisational literature, network governance represents the knowledge used for the network's overall functioning (Provan and Kenis 2008; Stoker 2006; Wegner et al. 2019). Three modes of governance (shared, lead-organization, and network administrative organization) shape critical factors of broadly defined network effectiveness (i.e., outcomes not achievable by individual organizations) (Mandell 1994). Within the process, three main tensions are identified: efficiency vs. inclusiveness, internal vs. external legitimacy, and flexibility vs. stability. Thus, information sharing processes' communal, social nature implies a self-governance capacity embedded within a range of heterogeneous market-actors who draw potential benefits from socio-technological uncertainties and opportunities (Lipshitz and Strauss 1997; Stieglitz et al. 2018).

Within organizational ecosystems, SMT communities of practice address day-today knowledge work characteristics, such as role modeling, mentoring, experiential learning, and reflection; provide developmental support that complements/enriches market-actors' existing work lives; and facilitate human/social and material (SMTs) agencies' intermingling (Kilduff and Tsai 2003; Lakshman and Rai 2019). These are non-linear articulations of multiple individuals' and collective's decisions of how to gradually move information in its physical form (in our case, patient data) to digital platforms. In other words, we move beyond debates whereby governments or firms' management coerce individual self-governance through legislation or threats of regulation, leaving little room for discretion and deviation (Gupta and Lad 1983) or firms observing agreed standards, such as interoperability and certification, to be profitable (King and Lenox 2000). While doing this, we follow work in the area of legal innovations (see Levillain and Segrestin 2019 regarding 'profit with purpose corporations'). We particularly recognize firms' accountability when steering the collective. A constituency's role within a network calls for understanding individuals' self-governance as a form of their accountability to themselves. Governance is no longer based on a business ethics form whereby powerful firms direct smaller suppliers; rather, it is built on every market-actor's daily activities.

Unlike broader governance arrangements involving governments (local or national), regulatory bodies, and supranational organizations that strongly influence the decision-making process, individual (non-heterogenous) actors employ selfgovernance at the micro level, deciding resource allocations amid an external environment's more limited influence (Ojo and Mellouli 2018). Self-governance, from a narrow perspective, is outlined as having control of one's own affairs and managing processes along ethical and socially responsible lines without coercion by punitive regulations (Gandini 2016; Gautam 2017). It has been growingly investigated in management and marketing literature showing that individuals.

Self-governance, as a tenet of B2B expertise sharing, implies actors act in both private and public decision-making spheres (Sørensen and Triantafillou 2013). Network governance can thus be applied to self-governance whereby market-actors selfmonitor their thinking and learning processes (Lajoie et al. 2013), form relationships with others (Maclaren 2009), and encourage autonomy (Oshana 2005) and reflection on action (Wickramasinghe 2010) and create new loci of power but caution against 
networks' negative effects, such as overbearing control and relational pressures (SMT trolls, polarized views, digital bullies) (Broniatowski et al. 2018).

\section{Framing and sensemaking e-detailing for knowledge workers and self-governance through SMT}

The study positioning, within self-governance and distributed innovation practices, reflects a framing situation on e-detailing in which SMTs and associated ecosystems can be considered as conceptual tools (Gal and Berente 2008). E-detailing is the main access point leveraged by MedTech firms via their medical science liaisons (MSLs-previously sale rep) to engage HCPs. It digitizes access to sales marketing content, mainly on mobile devices, making new product information (e.g., drugs, delivery mechanisms, test studies, etc.) interactive and updated in real time. It allows instantaneous data collection and tracking, generating a tailored high-quality experience for HCPs. E-detailing can facilitate awareness of specific products, but at the same time, it can create blind spots when data monetisation emerges from privatized access and strategy (as with FPSMT) and prevent a reasonable assessment of the global picture needed in therapy. E-detailing engagement and management encapsulates both promises and dilemma calling specifically for an investigation on self-governance accomplished by expert professionals who have to work on a daily basis to shape appropriate conditions for emerging actions along the problematized principles of legitimacy, efficiency, democracy, and accountability (Hennart 2015; Li 2003; Wedeman 2011).The leading pharmaceutical firm's (e.g., the SMT platform provider) position orchestrates the market-actors' endeavors, collective actions and network conditions for specific purposes. Framing embodies and structures the professionals' choices and reveals how they process information and IT resources and interact with peers (Orlikowski and Gash 1994). Beyond framing's technological interpretation, it incorporates the dynamic progress, uncertainties and inconsistencies SMTs represent (Van Burg et al. 2013). Framing, or frame creation, and sensemaking are considered complementary processes for understanding how market-actors can negotiate SMTs as a structuring context in which they are voluntarily embedded. Goffman (1974) viewed frames as abstractions that allow the configuration or structure of information meaning. The active process of seeking, processing and integrating information is labeled sensemaking (Wilson and Wilson 2013). Frames allow multiple (at times, contradictory) interpretations of shared SMT resources to become compatible and strengthen the voicing of tension (positive and negative) and encourage unusual solution searches. Through combined framing and sensemaking, we can understand and articulate how market-actors draw on formal and informal resources others create (Caughron et al. 2013) to impose a sense of control and decorum on themselves in a given ecosystem.

At the field level, framing allows interdependent market-actors to adopt uncommon answers to complex issues according to their beliefs (Cornelissen and Werner 2014). In highly regulated B2B ecosystems, sensemaking requires individuals to recognize the abstract resources they need and the organizational constraints they face. As a first step, this requires seeking, noting, and integrating new and often 
counterintuitive information that challenges one's original beliefs and attitudes (Weick et al. 2005). Then, sensemaking demands interaction and information sharing to capture the crowd's wisdom and guard against unintended data disclosures (Surowiecki 2005). In sum, one can use framing and sensemaking to appraise market-actors' social relationship investment and engagement processes.

Understanding this ambiguous refocusing process and how multiple actors' selfgovernance is practiced forms this study's core (Nalini et al. 2017). E-detailing, like all technologised practices, requires understanding not only technology acceptance (Abdekhoda et al. 2014) but also this acceptance's underlying meanings, including how health information management is negotiated within networks (Ehteshami 2017). At stake here, along with market pressures and innovations, is the understanding of how some platforms set up by facilitating private firms require the engagement of HCPs and their genuine willingness to positively contribute to the collective agenda that in essence raises drugs status away from a commodity to a valued innovation.

\section{Methodology}

\section{Overview}

Following Yin's (2015) and Eisenhardt's (1989) guidelines, we present a case study on e-detailing in the pharmaceutical industry to theorize self-governance as a practice based on B2B actors engagement with FPSMT in highly regulated contexts that has far-reaching implications for other industries such as banking, insurance or power generation. Case studies are recommended for unfolding events bounded by a specific time, multiple actors, and tasks (i.e., "a program, an event, an activity, a process, or one or more individuals" (Creswell and Creswell 2017, p. 15). A qualitative research approach was used to collect and analyze the data (Miles and Huberman 1994). The unit of analysis in this study is represented by three types of healthcare professionals, namely pharmaceutical salesforce called medical science liaisons (MSLs), physicians and pharmacists, representing the key current active market-actors engaged with FPSMT on one particular global pharmaceutical firm e-detailing platform. We apply established conventions of qualitative data analysis involving (1) categorization, abstraction, comparison integration, and abstraction searching for patterns in the data and why those characteristics are there towards consolidated meaning, and (2) interpretation, along essence-capturing of the essential elements of the stories connections (Spiggle 1994; Ng and Hase 2008).

\section{Setting}

Our interpretative analysis draws on 23 in-depth interviews conducted in Thailand, an emerging Asian market chosen because of the diverse and urgent healthcare issues it faces. Deloitte estimated health care spending in Thailand would reach $\$ 18.7$ billion in 2018, growing by $8 \%$ between 2014 and 2018 . This was higher than 
Malaysia's 4\%, Indonesia's 3.1\%, Myanmar's 1.8\%, and the Philippines' $4.4 \%$ and was on par with Singapore (Oxford Business Group 2020). In Thailand, more than $70 \%$ of the population receive free health care under universal health coverage, and the country is rapidly becoming a competitive destination for medical tourism. Moreover, private hospitals are raising funds and expanding overseas (Oxford Business Group 2020). Thailand has received recognition for its quality healthcare services, placing sixth (67.99/100) in CEOWORLD's 2019 Health Care Index out of 89 countries (Ireland 2019). Of the various subsets (all out of 100), Thailand received a score of 92.58 for its healthcare infrastructure, 17.37 for professionals' competence, 96.22 for healthcare cost, 67.51 for medicine availability, and 89.91 for government readiness (Bangkok Post 2019). Thus, e-detailing strategies seem to contribute to raising the somewhat lower scores for professional competence through Thailand's government establishing proactive policy strategies, making it the medical hub of Asia. Moreover, one key challenge the Thai healthcare system faces is to advance the capturing of accurate health data from different stakeholders to better plan and control spending. In data rich healthcare, e-detailing, if properly overseen, could foster sustainability of public healthcare expenditure (Khidhir 2019).

\section{Interviews}

\section{Interviewee selection and interview procedures}

One of this study's authors had full access to MSLs at a global pharmaceutical firm in Thailand. This allowed direct observation of daily services practices from its headquarters during video calls and face-to-face visits with HCPs. This access provided a solid foundation to observe individual practices, and meaningful interactions. An initial pilot study was carried out through three interviews. A semi-structured guide was created cycling between the pilot study and the literature (Davis and Eisenhardt 2011). Interviewing follows purposeful sampling (Teddlie and Yu 2007). Interviews were recorded with the interviewees' consent; when required, one of the researchers carried out translations, with pilot study respondents crosschecked for validity. Subsequently, an interview request was sent to $36 \mathrm{HCPs}$ if they had at least 15 interactions on the e-detailing platform (internal data); however, 13 of those declined participation for various reasons. For those that agreed, they were contacted via email and the generic topic was explained, along assurances of confidentiality and that ethical guidelines of the interviewing researcher's university would be followed. Therefore, we conducted a series of 23 in-depth interviews (face to face or via video links) with six physicians, seven pharmacists, and 10 MSLs (from a single global pharmaceutical firm) (see the Appendix). Respondents were from either public or private hospitals and had, on average, eight years of experience and were, on average, 32 years old; this was deemed appropriate to reflect and manage the complexity of the analytic task. All interviews were analyzed using the criterion of information saturation and redundancy (Lincoln and Guba 1985). Detailed notes were taken of specific examples shown by the HCPs (including screen shots of specific information on the e-detailing platform), photos of older leaflets, photos of 
how files were organized at the individual level, photos of IT equipment available, and displays of any drug or pharmaceutical firm names, if available. The aim of the interviews was for deep understanding of the interactions at stake in the e-detailing service, including the demands the informants perceived were put upon them (McCracken 1988).

\section{Interview questions framework and validity}

Twelve interview questions were divided into three parts: (a) how HCPs engage, or not, with FPSMT; (b) how HCPs change, or not, their work practices to echo the concepts of technological framing; and (c) how sensemaking engage HCPs towards self-governance (Järvinen et al. 2012; Kianto et al. 2016; Siamagka et al. 2015). Moving from general to more-specific questions, we asked about HCPs day-to-day experiences with e-detailing, including their experiences on pharmaceutical " $\mathrm{X}$ " e-detailing platform; approaches and managing the acquisition, creation, sharing, and retention of information; how those issues affect accomplishing their work (i.e., relevance of knowledge, effective process of knowledge evaluation and knowledge protection ability; evolvement of the FPSMT process with other professional actors (e.g., mutually beneficial decision-making process; better understanding of other market-actors' views regarding dispute resolution; daily practices and opportunities with "X" SMT and any restrictions or challenges they faced).

Content soundness was ensured by linking the semi-structured interview questions to the theoretical framework and through unpacking the framing and sensemaking processes in which market-actors' engagement in FPSMT becomes effective and self-governance is practiced. The protocol was reviewed by three experts within the global firm and was pre-tested by a representative of each profession, each of whom had more than 5-years' experience in healthcare. (After piloting, hospital managers and policymakers were not interviewed because they represented a more accounting-based view and were not directly involved in daily SMT activities.)

\section{Data analysis process}

To analyze the data, the authors systematically read the transcripts to search for ideas, patterns, common ground, and opposition within the respondents' answers. The analysis procedure included four steps: (a) researchers independently coded the practices identified through the interview transcripts and notes into preliminary working categories of informant-centric terms using NVivo version 10 to generate first-order themes; (b) shifting between the data and the literature (Santos and Eisenhardt 2009), second-order themes (Corbin and Strauss 1990) were developed; (c) the second-order themes were refined by cycling between theory and the field data (Davis and Eisenhardt 2011); and (d) at the end of this stage, three frames (aspiration, regulation and responsibilisation) were formed, and a framework was developed to demonstrate the relations among these concepts (see Fig. 1).

Initially we used open coding that generated a large number of open codes including for example: 'assertiveness to fit in', 'technology commitment and professional image', 


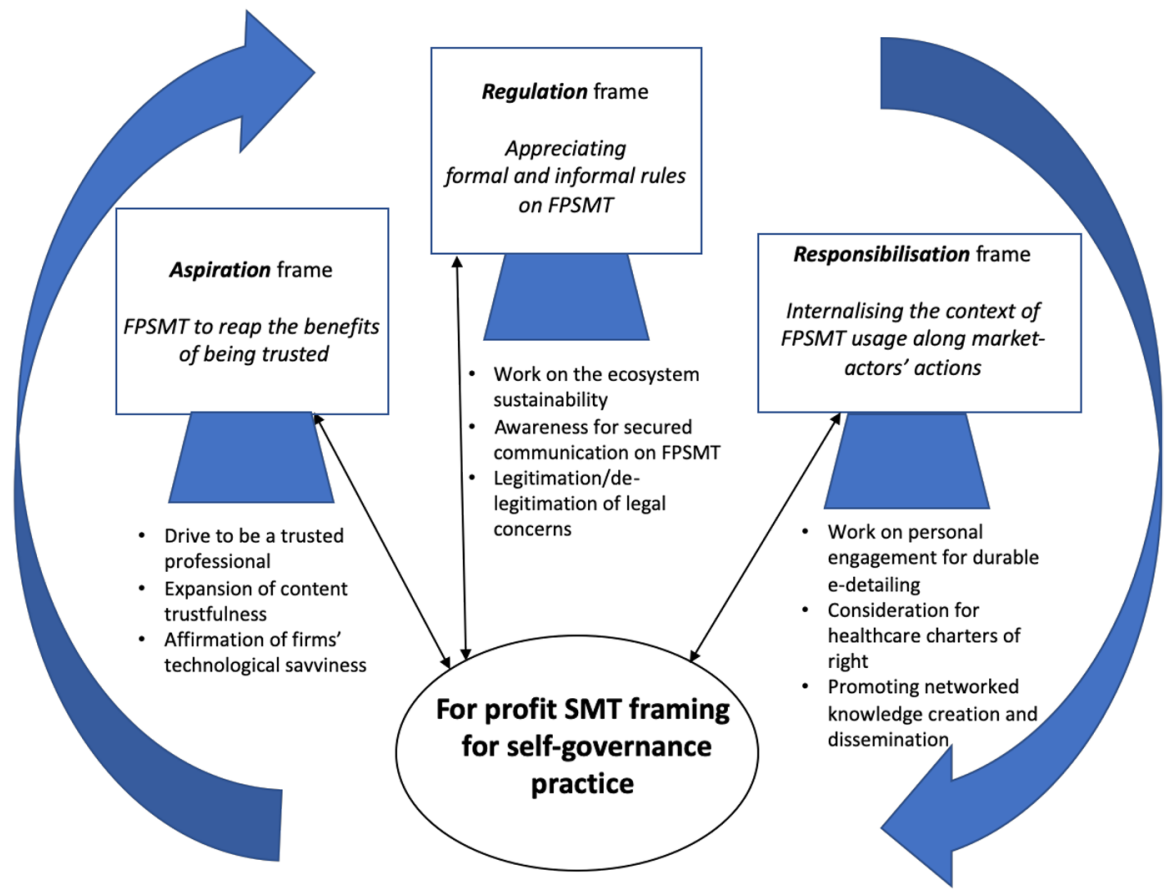

Fig. 1 Conceptual framework: FPSMT framing and self-governance practice

'tenability and accuracy', and 'e-detailing access and manipulation focuses'. Leveraging these multiple open codes, we mapped the mosaic of narratives without imposing a pre-imposed perspective (Yin 2015). The data revealed more details, and comparing the HCPs led to pattern and commonality recognition, such as respondents' underlining matters associated with information trust, IT-mediated information types (videos, graphs, photos), 'technological savviness', 'discussion modes standardisation' and 'information benchmarking and comparability'. By merging these materials, a higherlevel classification, 'expansion of content trustfulness' emerged. From that, we axial coded to identify central phenomenon (Davis and Eisenhardt 2011) and introduced additional search regarding specific positive and negatives examples about the challenges and opportunities faced on e-detailing to saturate the emerging higher-level classifications. Following Colliander and Wien (2013), the authors discussed the findings and resolved disagreements (Ng and Hase 2008; Spiggle 1994). In the last step, we theorized on these higher-level categories along the attributes highlighted in the literature review, leading to developing our three frames. 


\section{Findings}

The findings reveal that HCPs (pharmacists, physicians and MSLs) identify and seize opportunities offered on FPSMT in ways that disclose different reflective states through which along micro-practices self-governance practice is accomplished (see Fig. 1). The conceptual figure describes how market-actors develop a sense of purpose and appreciate the extent to which FPSMT continuously affects their own initiatives and development. As a reflective state, self-governance, through the questioning centered on each frame, encourages purposeful actions that ultimately foster active quests for relevance. The double-headed arrows in our framework represent the quests (i.e., self-governance practice as projects), which are often only partially resolved, leading market-actors to move to another frame. The three intertwined cognitive frames are labeled aspiration, regulation, and responsibilisation frames. The granularity of FPSMT is found to support market-actors' abilities to manoevre within multiple levels of competing rationalities, which then delineates the instantiation of self-governance practice. In each frame, we characterize the key micropractices, understood as individual activities abstracted from their specific context or time of application to appreciate how a phenomenon (here, self-governance) is instantiated. When being framed, these establish a teleoaffective structure toward self-governance as an integrative practice (Rouleau 2005). Micro-practices are understood as individual activities that have been abstracted from their specific context or time of application to appreciate how a phenomenon (here self-governance) is instantiated (Rouleau 2005).

\section{The aspiration frame: FPSMTs to reap the benefits of being trusted}

The respondents first revealed healthcare professionals rely on SMT to generate strong aspirations. Still, this aspiration frame relates both the humbling experiences and doubts about seizing control over one's career trajectories, competencies and effectiveness the development of FPSMT generates. Under this frame, respondents appeared to be critical towards FPSMT's present usage (i.e., current rules and obligations are considered problematic). The following quote from Respondent I illustrates that cognition triggers a readiness to be critical on the current state of FPSMT. However, both Respondents I and B pointed towards novel micro-practices that encourage the development of social agilities based on interactive, dynamic communication and trust in self-governance purposes.

Respondent I (pharmacist): I found fascinating that the detailed video showing how available drug molecules can deliver to targeted organs. It is very clearly explained and also encouraged me to understand it better, maybe from another perspective and in greater detail. It encouraged me to discuss, share and comment [on] the video with others to create further value.

Respondent B (physician): I can update to the new guideline of treatment and get the knowledge from the most famous professor's experience, all shared on one SM platform. I can adapt that information to use with my 
patients. I questioned myself. This application helped my hospital to save time and cost. It is real progress for all.

These market-actors displayed an obvious enthusiasm for SMT functionalities that change and strengthen network members, hence, positively enhancing their self-presentations. For most HCPs, technology-mediated interactions are related to the willingness to deepen content quality, which is directly linked to the inseparability of hardware, software and resource creation that facilitate the "professional social game." This frame supports the affordances of technological tools that articulate both individual and collective aspirations, including developing capacities to confront change. HCPs feel empowered by FPSMT they can use to answer multiple questions about the directionality and prescription of what is then a prescriptive disseminating tool.

With professional FPSMT usage, HCPs must adopt a higher level of vigilance and prudence compared to private SMT usage. The aspiration frame reflects what the mastery or obligations related to FPSMT (demands and expected outcomes) calls for in terms of SMT's scope and how to engage with it (e.g., assessment, conformity or deviation) when considering higher-order interests and flow of experiences. Through this reflective process, the aspirational values that individuals share on FPSMT are not suppressed by the personal risks these technologies epitomize; on the contrary, they are embraced towards innovation. However, Respondent $\mathrm{H}$ voiced an awareness of the danger that may come from adverse event cases.

Respondent H (MSL): I used e-detailing SMTs [...] to provide information to doctors, but often needed to smooth the discussion because of internet signal issues and legal requirements.... if a salesperson is not familiar with e-detailing or iPad technology, he will not use it naturally, the knowledge of technology itself is an issue. This can cause professional image damages. But it is getting better, and everybody can see that!

The aspiration frame subsequently involves making sense of the contradictions included in FPSMT's daily usage. This is akin to imposing a constant oversight reflecting "perceived absolute" demands (e.g., respect of the legal framework) beyond the innovative mindset that encourages active actors to make sense of direct interactions. Overall, the aspirational frame allows market-actors to work on professional sustainability and the development of content accuracy, and it even asserts specific firm's technological savviness, as Respondent $\mathrm{H}$ explained:

Respondent H (MSL): Slides presentation and sponsorship must be approved by [country level organisation] medical first and the legal guys [within the firm]. Slide presentation cannot have [a] trade name appearing because we are not doing business only but [must] focus on education and needs for information. Then we need to be very clear among ourselves on what we say how we interpret what is written. Otherwise, our jobs could be at risk. This forces all of us to reflect on what and how we want to use the material and how physicians will interpret and react to what is said. 
Although this quote reveals a fearful side of communication and misuse of privilege, respondents accentuate a possible set of reasoned usage that, as a group, they feel exposes the learning scope on FPSMT. Here, aspiration expresses the social nature of networks grounded in experience-based reassurance.

\section{The regulation frame: appreciating formal and informal rules on FPSMT}

In the regulation frame, respondents elaborated on the corollary of the relative empowerment described in the aspiration frame. In this frame, market-actors are better equipped to appraise their need for regulation for both formal and informal communication and sharing rules. As such, SMT is perceived as not appropriately or sufficiently scrutinized (towards correcting errors or incorrect information), especially when mutual support could clearly lead to richer, more valuable outcomes. Going beyond stereotyping, substantial concerns exist about the security of SMT (including privacy issues) and about the (de)legitimisation of legal issues, as evidenced in Respondent P's remarks.

Respondent $\mathbf{P}$ (MSL): In my opinion, there are many concerns... perhaps, confidentiality concerns, security network, accuracy and reliability of the information should be made clear when using digital media. It is about "patient's rights" because if users took a photo of a patient or shared a patient's OPD card on the platform or sent to others without erasing/blurring the patient's name/face, it would be illegal and violate the patient's rights. It is about accuracy concerns. To get rapid feedback on things[,] because if pharma marketers publish any mistakes, despite all the checks; or incorrect information, danger can spread very quickly, and the problem will be very hard to solve, SMTs seem to have a tendency not to let information even false [information] be erased.

Indeed, respondents developed various dispositions and sensibilities towards FPSMT guidelines and status beyond the blanket notice-and-consent model. Most respondents discussed the necessity of instigating, fostering and achieving protocols that do not curb communication, so that knowledge diffusion occurs, as Respondent N shows.

Respondent N (pharmacist): It surely supports pharmaceutical marketing but also innovation. We need it. I always search for medicine information on the doc. They share, but often I am not able to find much beyond normal information on traditional leaflets. Thus, I think that if pharmaceutical companies upload more information about their medicines or delivery mechanisms on their platform, we will conveniently access that essential information, will participate [in feedback, reviews] and use the drug, if appropriate, in our work.

Caught by the regulation frame, market-actors' self-governance practices tend to touch on both legal requirements and social communication expectations, demonstrating a need to further externalize FPSMT social evaluation across a broader set of actors. This frame allows market-actors to shape suitable strategies and, 
concurrently, be considered valued and trusted pioneers. Still, when actors engage in and challenge complex sociotechnical values, they recognize the unequally distributed risk to an individual's reputation. This encourages them to scrutinize specific market-actors', like the government's, initiatives, as Respondent K mentioned. Generally, rather than describing inertia, the regulation frame calls and relies on the other two frames (aspiration and responsibilisation) to shape market-actors' selfgovernance directionality and prescriptions towards fully exploiting what FPSMT can bestow on them.

Respondent K (MSL): Thai regulation has many particular rules about digital communication. Therefore, maybe one isn't brave enough to be the digital marketing leader among the pharmaceutical industry in Thailand. We are not all equal according to the government policies[,] you know. But we all need a voice, and we know stuff; the society needs it.

\section{The responsibilisation frame: internalizing the context of FPSMT usage along market-actors' actions}

This frame provides further evidence that market-actors work along an enquiring continuum and are thus aware of FPSMT usage's transformative and far-reaching implications on healthcare. This frame calls market-actors to problematise their engagement, which allows more socially valuable networked e-detailing practices, as Respondent $\mathrm{H}$ noted.

Respondent H (MSL): All actors may resist [SMT] change. In my opinion, sometimes it is too quick to change[,] but it is required to keep up with innovation and encourage improvement. I am familiar with the existing e-detailing, but all the time[,] I have to re-learn through physicians' comments and views. Value must be developed together.

The data illustrate that reflections are open on the exclusive charters and conditions in which healthcare professionals operate. Respondent A illustrates the thin line between grounding privileged communication and the carelessness of actions on FPSMT. Within the responsibilisation frame, time (or the lack of it) is a precious resource for all market-actors and is a central mechanism in fostering (or not) robust interactions. As such, Respondent A's quotation illustrates timely contextual actions' saliency, revealing market-actors must operate in symbiosis with the dynamic environment. This attempt to reach unification through FPSMT's use is portrayed as depending on responsible, collaborative learning as an impetus for communication that creates knowledge flows beyond facts.

Respondent A (physician): Digital media absolutely support marketing of pharmaceutical companies. They do not only benefit them but also benefit patients because it is a necessary condition to share information in modern medicine. Pharma firms use digital media such as media graph and e-detailing to create contents, spot patterns and gain best physicians' attention, but nothing is straightforward. 
The next quote from Respondent Q illustrates concerns that responsibilization must transpire across all market-actors (not only privileged ones) who adjust their behaviors and performance accordingly while recognizing that more traditional and differently codified offline practices (here, conferences) must be combined with the emerging new systems.

Respondent Q (MSL): I cannot answer how much a webcast can influence a specific doctor's belief and behavior. I think this is the salesperson's responsibility to follow up again and again maybe face to face or at a conference as we are creating behaviors. I find out information, with statistics from the platform after the webcast is finished about the actions taken or not taken. It is about developing comfortable communication. It is not one system or another.

Taken together, the three frames and sensemaking processes represent three pairs of binoculars B2B market-actors leverage in interpreting the unsettled communication on FPSMT within the healthcare ecosystem. These allow them to sustainably shape actions and engage in the digital knowledge work economy.

\section{Discussion}

The paper sets out to investigate how self-governance practice allows professionals in the digital knowledge economy to leverage SMT within highly regulated B2B environments while actively engaging in continuous knowledge work. Specifically, we show empirically how, in the case of healthcare in Thailand, such engagements operate in e-detailing. In doing so, self-governance practice is found to be generated through HCPs and MSLs' reliance on cognitive framing. It allows HCPs and MSLs to strengthen their position within FPSMT mediated practices. In the context of the highly regulated B2B healthcare social media ecosystem, the data emphasize how through the interdependence of three specific frames, self-governance operates as a practice leading to: (a) aspiration related to the benefits of being trusted, (b) regulation in ways that allow to appreciate formal and informal rules and (c) responsibilisation representing SMT's context internalization for daily usage and viable engagement in e-detailing practices. The three frames are akin to a process accentuating every market-actor's voice, richness, and role in open strategisation and organizing practice, in effect bringing professionals together (Whittington et al. 2011). FPSMT for self-governance underlies a range of possibilities for expert professionals related to where and how to positively contribute to the healthcare ecosystem beyond contingencies related to the here and now (i.e., complacency) (Broniatowski et al. 2018). It illustrates how distinct professional actors legitimize or delegitimise emerging digital practices (e.g., knowledge re-use, distributed leadership) by voicing opinions, expressing empathy, or relying on daily tactics. Collectively, the frames explain how engagement with privatized SMT incorporates information sharing through sensemaking in knowledge economies. This leads individuals to a more organized sense of self-governance (Burchell et al. 1991) and ways to cope with the inventive features of networks in a digital era. 


\section{Theoretical contribution}

While analyzing the healthcare sector in Thailand, this research contributes to the management literature by bringing a novel understanding of self-governance in the digital economy in two main ways. First, we give account of how selfgovernance operates in B2B contexts. Second, by delving into a cognitive framing approach, we bring to the fore a novel understanding of how self-governance for professional actors in the digital economy unfolds as a practice. Over the last decade, self-governance has primarily contributed to significant research in political sciences (Ostrom et al. 1992; Sørensen and Triantafillou 2013), management (Gautam 2017; Johnson et al. 2020; Park 2020), and marketing (Gandini 2016; Grénman et al. 2019). In doing so, it has largely ignored the forms self-governance take in digitized B2B contexts whereby the sense of professionalism is underpinned by the extensive set of tightly organized relationships and networked imperatives that are reflected in day-to-day managerial work (Fox and Ward 2008; Chelariu and Sangtani 2009; Olakivi and Niska 2017; Macheridis and Paulsson 2019). This study bridges this gap by proposing a view on self-governance that accommodates the increasing development of SMT within and between firms and the often conflicting expectations expert professionals face when being engaged in exchanges that advance both private and public interests (Wegner and Mozzato 2019). We show how self-governance as a digitized practice unfolds in situated practices through which professionals negotiate stakes related to personal aspirations, responsibilities, and regulatory concerns. As such, we offer an understanding of self-governance as a practice that places professionals as major actors on both private and public agenda who demonstrates a sense of professionalism by going beyond self-interests (Gandini 2016; Gautam 2017).

The data show that B2B market-actors are often encouraged to step into new roles they might initially find unfamiliar and that have to be established to meet collective needs. Dispersed expert professionals are critical sources of knowledge, interpretation, and elucidation. They shape complex social codes, rules, and technologies, including SMT, towards developing original, often unprecedented solutions with far-reaching effects on different dimensions of the corporate innovation process, reputation, and control beyond the narrow pursuit of sales' objectives (Wider et al. 2018). HCPs are now extensively embedded in their ecosystems, where different types of sustainable solutions can coexist, and where a wider array of expert professionals are able to keep momentum to influence the decision-making process. Beyond the healthcare sector and Asia, this research underlines that expert professionals' engagements via self-governance conjointly serve professionals individually, the collective agenda, and specific business dimensions (e.g., perception of products and service quality). Self-governance becomes here a central resource for network governance. We thus contribute to network governance research by showing the conjoint roles of innovative governance structures (e.g., FPSMT) and professional engagement in the shaping of effective network governance. We specifically underline the worth of a practice-based view on self-governance to articulate the collaborative and competitive modes of conduct that prevail in network governance explicitly in highly regulated contexts (Wegner and Mozzato 2019). 


\section{Limitations and future studies}

Considering that this study has been conducted within a single country, its findings provide avenues for further research. Given the rapid development of e-detailing and B2B social media in Asia, a longitudinal approach may capture the ever-changing nature of situated practices related to self-governance. It would be also important to enhance the understanding of the roles played by various information technologies in self-governance practices. Future studies comparing managerial stances across organizational departments in B2B can add to the understanding of self-governance and network governance by exploring various countries and types of industries including the less regulated ones. Following the same logic, studies can investigate self-governance as a resource through which professionals negotiate governmental regulations in the case of non-mature marketplaces (e.g., second-hand goods or promotion of alternative lifestyle). Finally, to provide a more balanced view on how expert professionals draw on self-governance within networks, future research could determine how self-governance via social media platforms operates along various professional positions from trainees to CEOs. In relation to this, we call for specific research on self-governance that investigates professional actors whose actions on privatized social platforms led to negative consequences for them (e.g., job loss).

\section{Managerial implications}

For managers, our research shows that innovative governance structures in the digital economy, such as FPSMT, are powerful in developing expert professionals' confidence and autonomy. Professionals are indeed found to be going beyond what is strictly regulated and develop knowledge structures favoring innovations. Under these conditions, firm strategies can mobilize expert professionals to balance the voices of influential groups (e.g., scientific committees, lobby groups etc.). Our research echoes managers' challenges reflected in demand-side activities related to economies of scale or network effects when attempting to foster more inclusivity to forge a navigable path to collective welfare and innovation (Swani et al. 2017). Consequently, this study shows that on privatized and public SMT, B2B professionals are expected to go beyond mere views of information towards contributions to knowledge production. In sum, each professional is called to reflect on his/her active steering participation (e.g., boycotts, resistance, compliance etc.) to influence network-level changes (Coyle 2017).

The findings suggest that self-governance and privatized social media technologies (e.g., FPSMT) are at the core of a broader and deeper debate regarding professionals, firm and collective accountability, and the ways they question the value of globalized wealth sharing and associated impacts on business models. In the pharmaceutical sector, executive boards and leading CEOs will need to appreciate the worth of collective ways that foster innovation within more inclusive service orientated approaches. E-detailing now departs from push marketing strategies as it does not lock in actors and fosters individuals' openness to alternative solutions 
(Ehteshami 2017; Kwak and Chang 2016; Nalini et al. 2017). Along shifting regulations, key stakes for B2B firms are to enact relevant performance indicators (e.g., number of views, number of document downloads etc.) and associated rewards for MLSs. The study shows the relevance for firms in emerging market conditions to facilitate the understanding of how e-detailing technology operates (e.g., tracking and adjustments of data in real time, regulatory constraints and prevailing netiquette). Spotting problematic behaviors allows firms to limit the occurrence of adverse events by taking early corrective actions, which in turn could limit the perceived intrusiveness of governments' interventions.

Coming to the case of e-detailing in Thailand, it is essential to underline that HCPs' possible non-engagement may endanger the country's healthcare system (Oxford Business Group n.d). Indeed, the findings underline that the local public and private hospital management is welcoming digital access to support modern medicine. At stake here is the welcoming of individual expert professionals' voices that contribute to bring medical solutions in all parts of the country and allow medicine sales to fit better with demand. Conveying local information appears here as being essential to strengthen healthcare system's responsiveness and be less vulnerable to unanticipated events such as pandemic (e.g., COVID-19) or natural disasters. This implies that the Thai government develops a robust healthcare system by documenting all the processes and harnessing data to support expert professionals' reskilling and upskilling capacities (Bangkok Post 2019).

\section{Compliance with ethical standards}

Conflict of interest On behalf of all authors, the corresponding author states that there is no conflict of interest. 


\section{Appendix: Respondents' overview}

\begin{tabular}{lllllc}
$\begin{array}{c}\text { Respondent } \\
\text { Code }\end{array}$ & \multicolumn{1}{c}{ Role } & \multicolumn{1}{c}{ Workplace } & \multicolumn{1}{c}{ Education level } & Age & $\begin{array}{c}\text { Year of Work } \\
\text { Experience }\end{array}$ \\
Respondent A & Physician & Government Hospital & Specialist (Pediatric) & 38 & 13 \\
Respondent B & Physician & Government Hospital & Specialist (Pediatric) & 30 & 5 \\
Respondent C & Pharmacist & Private Hospital & Bachelor of Pharmacy & 27 & 3 \\
Respondent D & Pharmacist & Private Hospital & Bachelor of Pharmacy & 27 & 3 \\
Respondent E & Salesforce & Pharma Co. Thailand & Bachelor of Pharmacy & 30 & 7 \\
Respondent F & Salesforce & Pharma Co. Thailand & Bachelor of Nursing & 52 & 25 \\
Respondent G & Salesforce & Pharma Co. Thailand & Bachelor of Science & 41 & 20 \\
Respondent H & Salesforce & Pharma Co. Thailand & Bachelor of Pharmacy & 28 & 4 \\
Respondent I & Pharmacist & Government Hospital & Bachelor of Pharmacy & 27 & 3 \\
Respondent J & Pharmacist & Private Hospital & Bachelor of Pharmacy & 27 & 3 \\
Respondent K & Salesforce & Pharma Co. Thailand & Bachelor of Science & 40 & 20 \\
Respondent L & Salesforce & Pharma Co. Thailand & Bachelor of Pharmacy & 36 & 11 \\
Respondent M & Salesforce & Pharma Co. Thailand & Bachelor of Science & 30 & 5 \\
Respondent N & Pharmacist & Government Hospital & Bachelor of Pharmacy & 27 & 3 \\
Respondent O & Salesforce & Pharma Co. Thailand & Bachelor of Pharmacy & 32 & 8 \\
Respondent P & Salesforce & Pharma Co. Thailand & Bachelor of Pharmacy & 31 & 8 \\
Respondent Q & Salesforce & Pharma Co. Thailand & Bachelor of Pharmacy & 34 & 10 \\
Respondent R & Physician & Government Hospital & ENT Specialist & 31 & 6 \\
Respondent S & Physician & Government Hospital & General Practice & 36 & 11 \\
Respondent T & Pharmacist & Government Hospital & Bachelor of Pharmacy & 26 & 3 \\
Respondent U & Pharmacist & Government Hospital & Bachelor of Pharmacy & 27 & 3 \\
Respondent V & Physician & Government Hospital & Resident Medicine & 30 & 5 \\
Respondent W & Physician & Government Hospital & Resident Medicine & 29 & 5
\end{tabular}

\section{References}

Abdekhoda, M., Ahmadi, M., Dehnad, A., \& Hosseini, A. F. (2014). Information technology acceptance in health information management. Methods of Information in Medicine, 53(01), 14-20.

Ammirato, S., Felicetti, A. M., Della Gala, M., Aramo-Immonen, H., Jussila, J. J., \& Kärkkäinen, H. (2019). The use of social media for knowledge acquisition and dissemination in B2B companies: An empirical study of Finnish technology industries. Knowledge Management Research \& Practice, 17(1), 52-69.

Bangkok Post. (2018). Is the future of Thailand's health care in danger? Retrieved from https://www. bangkokpost.com/opinion/opinion/1419643/is-the-future-of-thailands-health-care-in-danger-

Bangkok Post. (2019). Thailand's healthcare ranked sixth best in the world. Retrieved from https ://www.bangkokpost.com/thailand/general/1746289/thailands-healthcare-ranked-sixth -best-in-the-world

Baptista, J., Wilson, A. D., Galliers, R. D., \& Bynghall, S. (2017). Social media and the emergence of reflexiveness as a new capability for open strategy. Long Range Planning, 50(3), 322-336.

Broniatowski, D. A., Jamison, A. M., Qi, S., AlKulaib, L., Chen, T., Benton, A., \& Dredze, M. (2018). Weaponized health communication: Twitter bots and Russian trolls amplify the vaccine debate. American Journal of Public Health, 108(10), 1378-1384.

Buratti, N., Parola, F., \& Satta, G. (2018). Insights on the adoption of social media marketing in B2B services. The TQM Journal, 30(5), 490-529.

Burchell, G., Gordon, C., \& Miller, P. (Eds.). (1991). The Foucault effect: Studies in governmentality. Chicago, IL: University of Chicago Press.

Caughron, J. J., Antes, A. L., Stenmark, C. K., Thiel, C. E., Wang, X., \& Mumford, M. D. (2013). Competition and sensemaking in ethical situations. Journal of Applied Social Psychology, 43, 1491-1507. 
Cawsey, T., \& Rowley, J. (2016). Social media brand building strategies in B2B companies. Marketing Intelligence \& Planning, 34(6), 754-776.

Chelariu, C., \& Sangtani, V. (2009). Relational governance in B2B electronic marketplaces: An updated typology. Journal of Business \& Industrial Marketing, 24(2), 108-118.

Clarke, A. (2018). Designing computer-based learning materials. London: Routledge.

Colliander, J., \& Wien, A. H. (2013). Trash Talk Rebuffed: Consumers' defence of companies criticized in online communities. European Journal of Marketing, 47(10), 1733-1757.

Corbin, J. M., \& Strauss, A. (1990). Grounded theory research: Procedures, canons and evaluative criteria. Qualitative Sociology, 13(1), 3-21.

Cornelissen, J. P., \& Werner, M. D. (2014). Putting framing in perspective: A review of framing and frame analysis across the management and organizational literature. The Academy of Management Annals, 8(1), 181-235.

Coyle, D. (2017). Precarious and productive work in the digital economy. National Institute Economic Review, 240(1), R5-R14.

Creswell, J. W., \& Creswell, J. D. (2017). Research design: Qualitative, quantitative, and mixed methods approaches. London: Sage Publications.

Davies, J. S. (2000). The hollowing-out of local democracy and the fatal conceit of governing without government. British Journal of Politics \& International Relations, 2(3), 414-428.

Davis, J. P., \& Eisenhardt, K. M. (2011). Rotating leadership and collaborative innovation: Recombination processes in symbiotic relationships. Administrative Science Quarterly, 56(2), 159-201.

de Kervenoael, R., Bisson, C., \& Palmer, M. (2015). Dissidents with an innovation cause? Non-institutionalized actors' online social knowledge sharing, solution-finding tensions and technology management innovation. Information Technology \& People, 28(3), 653-676.

Edosomwan, S., Prakasan, S. K., Kouame, D., Watson, J., \& Seymour, T. (2011). The history of SM and its impact on business. Journal of Applied Management and Entrepreneurship, 16(3), 79-91.

Ehteshami, A. (2017). Barcode technology acceptance and utilization in health information management department at academic hospitals according to technology acceptance model. Acta Informatica Medica, 25(1), 4.

Eisenhardt, K. M. (1989). Building theories from case study research. Academy of Management Review, 14(4), 532-550.

Esmark, A., \& Triantafillou, P. (2009). A Macro Level Perspective on Governance of the self and others. The Politics of Self-Governance, 25, 41.

Fox, N. J., \& Ward, K. J. (2008). What governs governance, and how does it evolve? The sociology of governance-in-action. British Journal of Sociology, 59(3), 519-538.

Gal, U., \& Berente, N. (2008). A social representations perspective on information systems implementation: Rethinking the concept of "frames." Information Technology \& People, 21(2), 133-154.

Gandini, A. (2016). Digital work: Self-branding and social capital in the freelance knowledge economy. Marketing Theory, 16(1), 123-141.

Gautam, A. (2017). Self-governance and responsibility in global times. International Journal of Research in Management \& Social Science, 5(3), 30.

Goffman, E. (1974). Frame analysis: An essay on the organization of experience. Cambridge, MA: Harvard University Press.

Golden, M. (2011). Social media strategies for professionals and their firms. Hoboken: Wiley.

Grénman, M., Hakala, U., \& Mueller, B. (2019). Wellness branding: insights into how American and Finnish consumers use wellness as a means of self-branding. Journal of Product \& Brand Management, 28(4), 462-474.

Grondys, K. (2019). Implementation of the sharing economy in the B2B sector. Sustainability, 11(14), 3976.

Gupta, A. K., \& Lad, L. J. (1983). Industry self-regulation: An economic, organizational, and political analysis. Academy of Management Review, 8, 416-425.

Hennart, J.-F. (2015). Leveraging Asian institutions to deepen theory: A transaction-cost perspective on relational governance. Asian Business \& Management, 14(4), 257-282.

Huotari, L., Ulkuniemi, P., Saraniemi, S., \& Mäläskä, M. (2015). Analysis of content creation in social media by B2B companies. Journal of Business \& Industrial Marketing, 30(6), 761-770.

Ireland, S. (2019, August 5). Revealed: Countries with the best health care systems, 2019. CEOWORLD Magazine. Retrieved from https://ceoworld.biz/2019/08/05/revealed-countries-with-the-best-healt h-care-systems-2019/. 
Järvinen, J., Tollinen, A., Karjaluoto, H., \& Jayawardhena, C. (2012). Digital and social media marketing usage in B2B industrial section. Marketing Management Journal, 22(2), 102-117.

Johnson, K. R., \& Bagatell, N. (2020). Negotiating tensions on the front line: Circuits of accountability and self-governance in institutional care of adults with intellectual disability. Work, Employment and Society, 34(4), 644-660.

Khidhir S. (2019). Healthcare: Why are Thais worried? The Asean Post. Retrieved from https://theas eanpost.com/article/healthcare-why-are-thais-worried.

Kianto, A., Vanhala, M., \& Heilmann, P. (2016). The impact of knowledge management on job satisfaction. Journal of Knowledge Management, 20(4), 621-636.

Kilduff, M., \& Tsai, W. (2003). Social networks and organizations. London: Sage Press.

King, A., \& Lenox, M. (2000). Industry self-regulation without sanctions: The chemical industry's responsible care program. Academy of Management Review, 43, 698-716.

Kwak, E. S., \& Chang, H. (2016). Medical representatives' intention to use information technology in pharmaceutical marketing. Healthcare Informatics Research, 22(4), 342-350.

Lajoie, S. P., et al. (2013). Technology-rich tools to support self-regulated learning and performance in medicine. In R. Azevedo \& V. Aleven (Eds.), International handbook of metacognition and learning technologies (pp. 229-242). New York: Springer.

Lakshman, C., \& Rai, S. (2019). The influence of leadership on learning and innovation: Evidence from India. Asian Business \& Management. https://doi.org/10.1057/s41291-019-00096-w

Leek, S., Canning, L., \& Houghton, D. (2016). Revisiting the Task Media Fit Model in the era of Web 2.0: Twitter use and interaction in the healthcare sector. Industrial Marketing Management, 54, 25-32.

Levillain, K., \& Segrestin, B. (2019). From primacy to purpose commitment: How emerging profit-withpurpose corporations open new corporate governance avenues. European Management Journal, 37(5), 637-647.

Li, J. S. (2003). Relation-based vs. rule-based governance: An explanation of the East Asian miracle and crisis. Review of International Economics, 11(4), 651-673.

Lincoln, Y. S., \& Guba, E. G. (1985). Naturalistic inquiry London. England: Sage Publications.

Lipshitz, R., \& Strauss, O. (1997). Coping with uncertainty: A naturalistic decision-making analysis. Organizational Behavior and Human Decision Processes, 69(2), 149-163.

Lomborg, S. (2017). A state of flux: Histories of social media research. European Journal of Communication, 32(1), 6-15.

Macheridis, N., \& Paulsson, A. (2019). Professionalism between profession and governance: How university teachers' professionalism shapes coordination. Studies in Higher Education, 44(3), 470-485.

Maclaren, K. (2009). Emotional metamorphoses: The role of others in becoming a subject. In S. Campbell, L. Meynell, \& S. Sherwin (Eds.), Embodiment and agency (pp. 25-45). University Park: Pennsylvania State University Press.

Mandell, M. (1994). Intergovernmental management in interorganizational networks: A revised perspective. International Journal of Public Administration, 11(4), 393-416.

Marwick, A., \& Hargittai, E. (2019). Nothing to hide, nothing to lose? Incentives and disincentives to sharing information with institutions online. Information, Communication \& Society, 22(12), 1697-1713.

Mazmanian, M. (2013). Avoiding the trap of constant connectivity: When congruent frames allow for heterogeneous practices. Academy of Management Journal, 56(5), 1225-1250.

McCracken, G. (1988). The long interview. London: Sage.

McTaggart, B., Barrins, S., \& McCarthy, J. (2017). Governing for excellence in the social care sectorthe role of self-governance in Ireland's evolving social care profession. International Journal of Practice-based Learning in Health and Social Care, 5(2), 84-100.

Miles, M. B., \& Huberman, A. M. (1994). Qualitative data analysis: An expanded sourcebook. London: Sage.

Moncrief, W. C., Marshall, G. W., \& Rudd, J. M. (2015). SM and related technology: Drivers of change in managing the contemporary sales force. Business Horizons, 58(1), 45-55.

Nalini, R., Alamelu, R., Amudha, R., Badrinath, V., \& Kumar, D. G. (2017). E-detailing-empowering doctors in digital era. Research Journal of Pharmacy and Technology, 10(8), 2663-2667.

$\mathrm{Ng}, \mathrm{K}$., \& Hase, S. (2008). Grounded suggestions for doing a grounded theory business research. Electronic Journal of Business Research Methods, 6(2), 155-170.

North, K., \& Kumta, G. (2018). Knowledge management: Value creation through organizational learning. New York: Springer. 
Ojo, A., \& Mellouli, S. (2018). Deploying governance networks for societal challenges. Government Information Quarterly, 35(4), S106-S112.

Olakivi, A., \& Niska, M. (2017). Rethinking managerialism in professional work: From competing logics to overlapping discourses. Journal of professions and organization, 4(1), 20-35.

Orlikowski, W. J., \& Gash, D. C. (1994). Technological frames: Making sense of information technology in organizations. ACM Transactions on Information Systems, 12(2), 174-208.

Oshana, M. A. L. (2005). Autonomy and self-identity. In J. P. Christman \& J. Anderson (Eds.), Autonomy and the challenges to liberalism: New essays (pp. 77-97). Cambridge: Cambridge University Press.

Ostrom, E., Walker, J., \& Gardner, R. (1992). Covenants with and without a sword: Self-governance is possible. American Political Science Review, 86(2), 404-417.

Oxford Business Group, ND. Robust growth expected in Thailand's health sector. Retrieved from https ://oxfordbusinessgroup.com/overview/health-check-despite-financial-challenges-sector-set-robus t-growth.

Oxford Business Group. (2020). Robust growth expected in Thailand's health sector. Retrieved from https ://oxfordbusinessgroup.com/overview/health-check-despite-financial-challenges-sector-set-robus t-growth.

Panahi, S., Watson, J. A., \& Partridge, H. (2016). Conceptualising social media support for tacit knowledge sharing: Physicians' perspectives and experiences. Journal of Knowledge Management, 20(2), 344-363.

Park, E. (2013). From academic self-governance to executive university management: Institutional governance in the eyes of academics in Europe. In U. Teichler \& E. A. Höhle (Eds.), The work situation of the academic profession in Europe: Findings of a survey in twelve countries (pp. 183-203). Dordrecht: Springer.

Parker, R. (2007). Networked governance or just networks? Local governance of the knowledge economy in Limerick (Ireland) and Karlskrona (Sweden). Political Studies, 55(1), 113-132.

Pascucci, F., Ancillai, C., \& Cardinali, S. (2018). Exploring antecedents of social media usage in B2B: a systematic review. Management Research Review, 41(6), 629-656.

Provan, K. G., \& Kenis, P. (2008). Modes of network governance: Structure, management, and effectiveness. Journal of Public Administration Research and Theory, 18(2), 229-252.

Razmerita, L., Kirchner, K., \& Nielsen, P. (2016). What factors influence knowledge sharing in organizations? A social dilemma perspective of social media communication. Journal of Knowledge Management, 20(6), 1225-1246.

Rooderkerk, R. P., \& Pauwels, K. H. (2016). No comment?! The drivers of reactions to online posts in professional groups. Journal of Interactive Marketing, 35, 1-15.

Rouleau, L. (2005). Micro-practices of strategic sensemaking and sense giving: How middle managers interpret and sell change every day. Journal of Management Studies, 42, 1413-1441.

Santos, F. M., \& Eisenhardt, K. M. (2009). Constructing markets and shaping boundaries: Entrepreneurial power in nascent fields. Academy of Management Journal, 52(4), 643-671.

Schor, J. (2016). Debating the sharing economy. Journal of Self-Governance and Management Economics, 4(3), 7-22.

Siamagka, N. T., Christodoulides, G., Michaelidou, N., \& Valvi, A. (2015). Determinants of social media adoption by B2B organizations. Industrial Marketing Management, 51, 89-99.

Sivalingam, G. (2010). Network governance in Malaysia's telecommunications industry. Asia Pacific Business Review, 16(1-2), 143-159.

Sørensen, E., \& Triantafillou, P. (Eds.). (2013). The politics of self-governance. Farnham: Ashgate Publishing Ltd.

Spiggle, S. (1994). Analysis and interpretation of qualitative data in consumer research. Journal of Consumer Research, 21(3), 491-503.

Stieglitz, S., Bunker, D., Mirbabaie, M., \& Ehnis, C. (2018). Sense-making in social media during extreme events. Journal of Contingencies and Crisis Management, 26(4), 1-15.

Stoker, G. (1998). Governance as theory: Five propositions. International Social Science Journal, 155, $17-28$.

Stoker, G. (2006). Public value management: A new narrative for networked governance? The American review of public administration, 36(1), 41-57.

Surowiecki, J. (2005). The wisdom of crowds. New York: Doubleday.

Swani, K., Milne, G. R., Brown, B. P., Assaf, A. G., \& Donthu, N. (2017). What messages to post? Evaluating the popularity of social media communications in business versus consumer markets. Industrial Marketing Management, 62, 77-87. 
Teddlie, C., \& Yu, F. (2007). Mixed methods sampling. Journal of Mixed Methods Research [online], $1(1), 77-100$.

Unmetric.com. (2019). 7 social media trends in the pharmaceutical industry. Retrieved from https:// unmetric.com/resources/pharma-social-media-trends-report

Van Burg, E., Berends, H., \& van Raaij, E. M. (2013). Framing and interorganizational knowledge transfer: A process study of collaborative innovation in the aircraft industry. Journal of Management Studies, 1(3), 349-378.

Van den Berg, A. C., \& Verhoeven, J. W. (2017). Understanding social media governance: Seizing opportunities, staying out of trouble. Corporate Communications: An International Journal, 22(1), 149-164.

Wang, W. Y., Pauleen, D. J., \& Zhang, T. (2016). How social media applications affect B2B communication and improve business performance in SMEs. Industrial Marketing Management, 54, $4-14$.

Wathne, K. H., \& Fjeldstad, Ø. D. (2019). Where do we go from here? The future of B2B governance research. Journal of Business \& Industrial Marketing, 35(4), 623-627.

Wedeman, A. (2011). Corruption and good governance in Asia. Asia Business \& Management, 10, $453-455$.

Wegner, D., \& Mozzato, A. R. (2019). Shall we cooperate, or shall we compete? How network learning episodes influence strategic decisions in strategic networks. International Journal of Management and Enterprise Development, 18(3), 171-188.

Wegner, D., Teixeira, E. K., \& Verschoore, J. R. (2019). Modes of network governance: What advances have been made so far? Revista Base (Administração e Contabilidade) da UNISINOS, 16, 1.

Weick, K. E., Sutcliffe, K. M., \& Obstfeld, D. (2005). Organizing and the process of sensemaking. Organization Science, 16(4), 409-421.

Whittington, R., Cailluet, L., \& Yakis-Douglas, B. (2011). Opening strategy: Evolution of a precarious profession. British Journal of Management, 22, 531-544.

Wickramasinghe, N. (2010). Evaluation of human action: Foucault's power/knowledge corollary. In M. Saito, N. Wickramasinghe, M. Fujii, \& E. Geisler (Eds.), Redesigning innovative healthcare operation and the role of knowledge management (pp. 106-124). s.1.: ICI Global.

Wider, S., von Wallpach, S., \& Mühlbacher, H. (2018). Brand management: Unveiling the delusion of control. European Management Journal, 36, 301-305.

Wilson, M. J., \& Wilson, M. L. (2013). A comparison of techniques for measuring sensemaking and learning within participant-generated summaries. Journal of the American Society for Information Science and Technology, 64(2), 291-306.

Yin, R. K. (2015). Qualitative research from start to finish. New York: Guilford Publications.

Publisher's Note Springer Nature remains neutral with regard to jurisdictional claims in published maps and institutional affiliations.

Ronan de Kervenoael is a Professor of Marketing at Rennes School of Business in France. His wider research interests lie under the umbrella of retail, technology and consumer behaviour, including the study of social, cultural, and technological transformations in how consumers and firms (re)organize their lives or strategies. His work has been published in Environment \& Planning A, World Development, European Journal of Operational Research, Tourism Management, Information Technology and People, Journal of Retailing and Consumer Services, Service Industries Journal, Telecommunication Policy, International Journal of Retail Distribution Management and Consumption Markets \& Culture.

Alexandre Schwob is an Associate Professor of Marketing at Excelia Business School in France. His main research interests are digital transformation and Consumer Culture Theory (CCT). His research addresses these topics in various kinds of environments both from consumer and companies' perspectives. In his publications, whether in Tourism Management, Information Technology \& People, Journal of Consumer Behaviour, Consumption Markets \& Culture, Journal of Retailing and Consumer Services or in books such as Research in Consumer Behavior and Advances in Consumer Research, Alexandre has aimed to understand the stakes of digital consumption. He is particularly interested by the way marketactors make sense and shape digital technologies and marketing strategy. 
Inci Toral Manson is a lecturer in Marketing at Birmingham University in the UK. Prior to academia, she has worked as a senior manager in the retail banking industry and as a project manager for a range of technology and banking institutions. Her research focuses on digital marketing, retailing, strategic marketing, social media marketing, B2B marketing and blended learning pedagogy. She has presented her work in numerous academic conferences including Recent Advances in Retailing and Services Science, European Marketing Academy, British Academy of Management, and European Academy of Management.

Chatlada Ratana has an Msc Business and Management (Merit) degree from the Aston University. She has a particular interest in innovation management and Pharmaceutical retail industry. She is a product manager at Zuellig Pharma in Bangkok, Thailand.

\section{Affiliations}

\section{Ronan de Kervenoael ${ }^{1}$ (D) Alexandre Schwob ${ }^{2} \cdot$ Inci Toral Manson $^{3}$. Chatlada Ratana ${ }^{4}$}

Alexandre Schwob

schwoba@excelia-group.com

Inci Toral Manson

i.n.toral.1@bham.ac.uk

Chatlada Ratana

chatlada.rtn@gmail.com

1 Department of Marketing, Rennes School of Business, Rennes, France

2 Department of Marketing, Excelia Business School, La Rochelle, France

3 Department of Marketing, Birmingham University, Birmingham, UK

4 Aston University, Birmingham, UK 